\title{
Analysis of Mutual Language Intelligibility of the Programming Tool Used in Robot Programming Learning
}

\author{
Se-min Kim ${ }^{1}$, Chang-su Ryu ${ }^{2}$ and Choong Ho Lee ${ }^{3^{*}}$ \\ ${ }^{1}$ Graduate School of Information Communication Engineering, \\ Hanbat National University \\ ${ }^{2}$ Department of Cartoon \& Animation, Yewon Arts University \\ ${ }^{3}$ Graduate School of Information Communication Engineering, Hanbat National \\ University \\ 1'imsim303@hotmail.co.kr, ${ }^{2}$ twin4me@hotmail.com, ${ }^{3}$ chlee@hanbat.ac.kr
}

\begin{abstract}
In the Republic of Korea, several policies and studies are underway to organize a software curriculum into a regular course. In this study, we compared and analyzed several programming tools available in the robot programming learning activities of the software curriculum. Programming tools utilized in this study were MSRDS VPL and App Inventor and these were performed in a class by utilizing robots. As students can easily learn the foreign language similar to their mother tongue, this study examined how easily students were able to learn another programming language with a similar interface.
\end{abstract}

Keywords: Software Education, MSRDS, App Inventor, Block Type Programming

\section{Introduction}

The 21st century we live has entered a knowledge-oriented society due to the development of ICT skills. The developed various information-based technologies and application technologies have applied to many fields [1], and the development of the information communication technology such as wireless internet, mobile internet devices and the Internet of Things has given an impact on an educational environment. Such a society pursues the human who is not standardized by monolithic education but thinking creatively about what is happening in the world and able to actively respond to changes in a given environment. Therefore, new education which can cultivate a creative problemsolving ability on the basis of creativity is required, not the former education doing such as rote learning and cramming education [3]. In the Republic of Korea, the information curriculum of elementary and secondary education was renamed as the software curriculum, and the curriculum was revised to teach software based on Computational Thinking. Universities are seeking changes for carrying out software education for all students. In particular, Ministry of Science, ICT and Future Planning is working for training software-talented individuals by supporting 11 billion won for six years as a supporting business of software-oriented university at the national level [4]. In this study, we compared MSRDS VPL and App Inventor with C language in class and we used robots as educational materials. This study tried to find out the mutual language intelligibility among languages.

\section{Related Research}

\subsection{Preceding Research}

C. J. Park (2015) analyzed the relationship among the abstract thinking, language intimacy, and study achievement about the understanding of $\mathrm{C}$ and Scratch program. Park 
showed that $\mathrm{C}$ and Scratch were main languages which the students of the study had experienced before, and the language intimacy of Java or Visual Basic affected students' abstract thinking skills positively.

S. W. Seo (2010) compared the text-based programming languages with the visualbased programming languages. Seo concluded that the text-based programming languages affected the improving thinking ability of science of information more meaningfully than the visual-based programming languages [6].

\subsection{Programming Tools}

This study has investigated the keyword, mutual language intelligibility among several programming tools. It is easy to learn a foreign language which is very similar mutually. MSRDS (MicroSoft Robotics Developer Studio) is developing tools and an environment that help to facilitate the development of various robotic applications if professional workers or ordinary people have general knowledge of robot programming. Figure 1 and Figure 2 shows a programming result as if there were robot equipment [7].

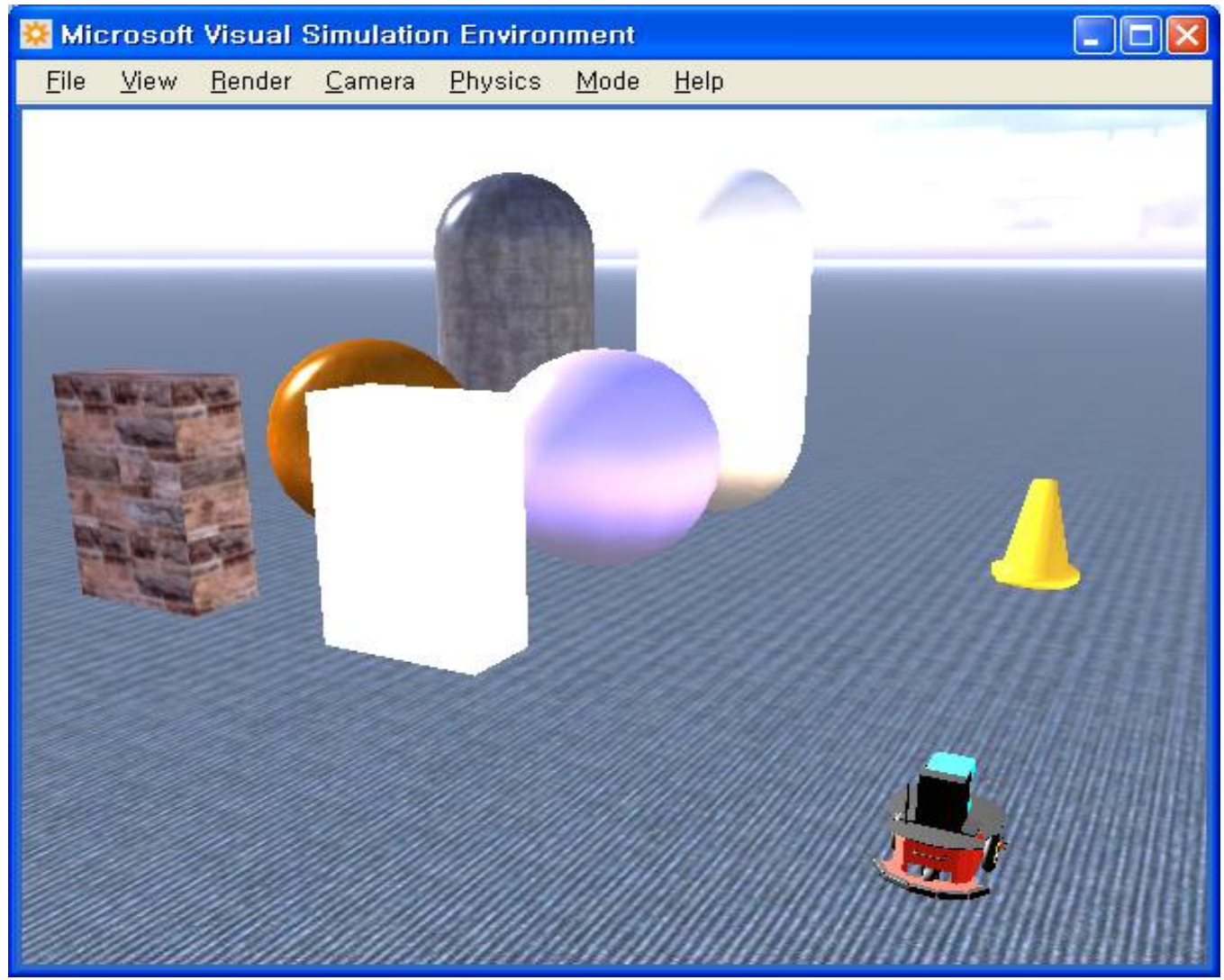

Figure 1. Robotics Simulation (Keyboard Control) 


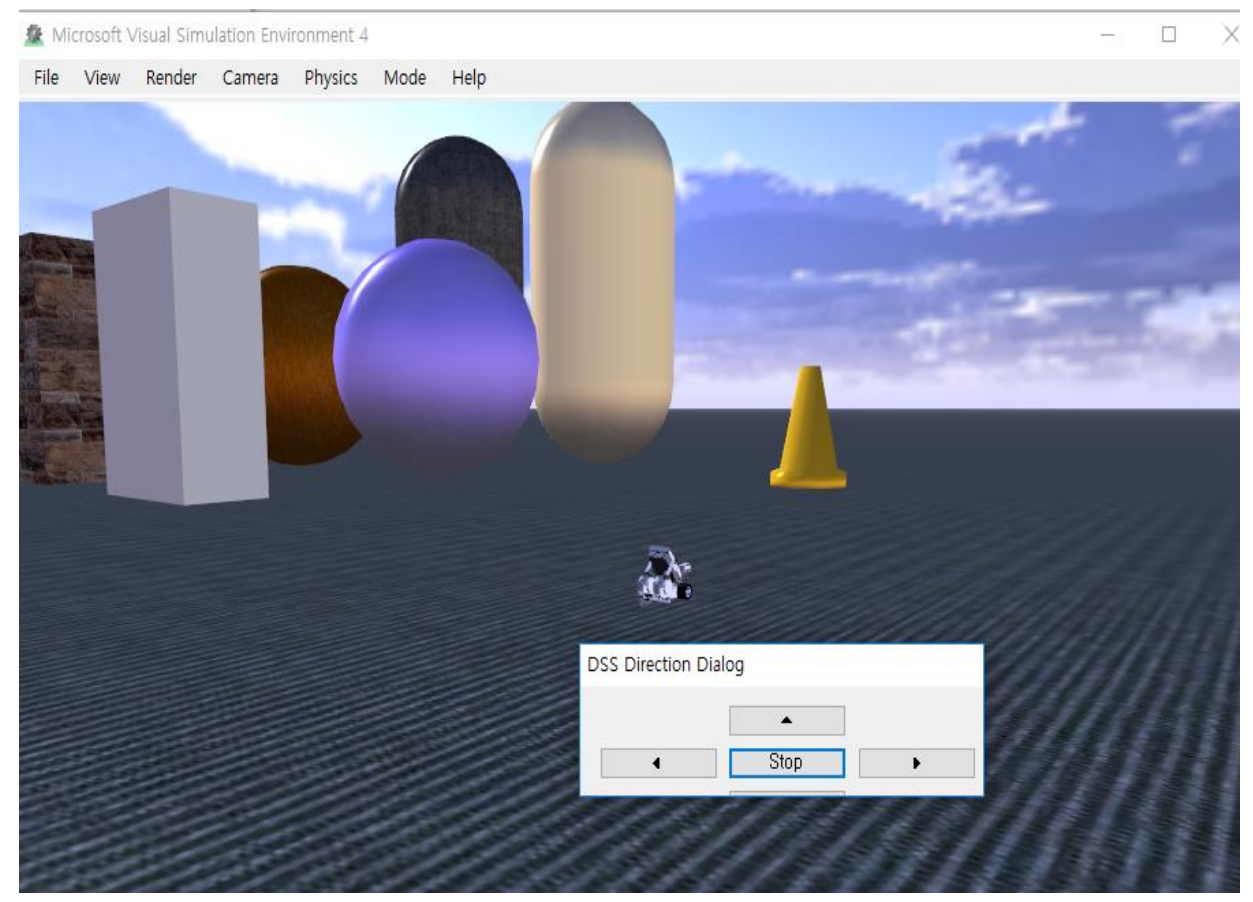

Figure 2. Robotics Simulation (Direction Dialog Control)

VPL (Visual Programming Language) helps people do programming by connecting lines between icon-based shapes named Activity as shown in Figure 3 and Figure 4. Also, VPL helps easily to understand the basic concepts of programming and very usefully to grasp the principles of the programming.

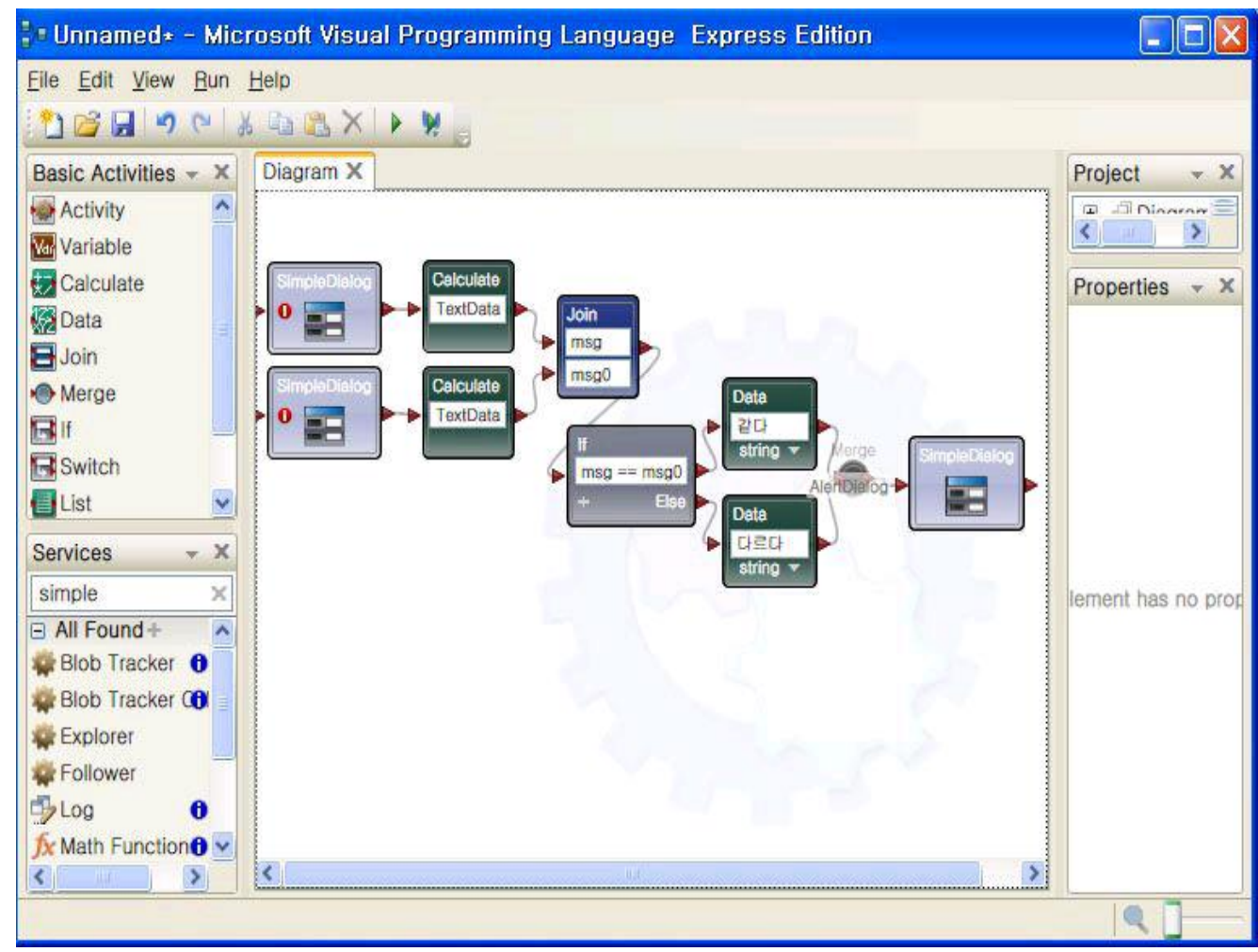

Figure 3. Source Code Programming by VPL (Level Low) 


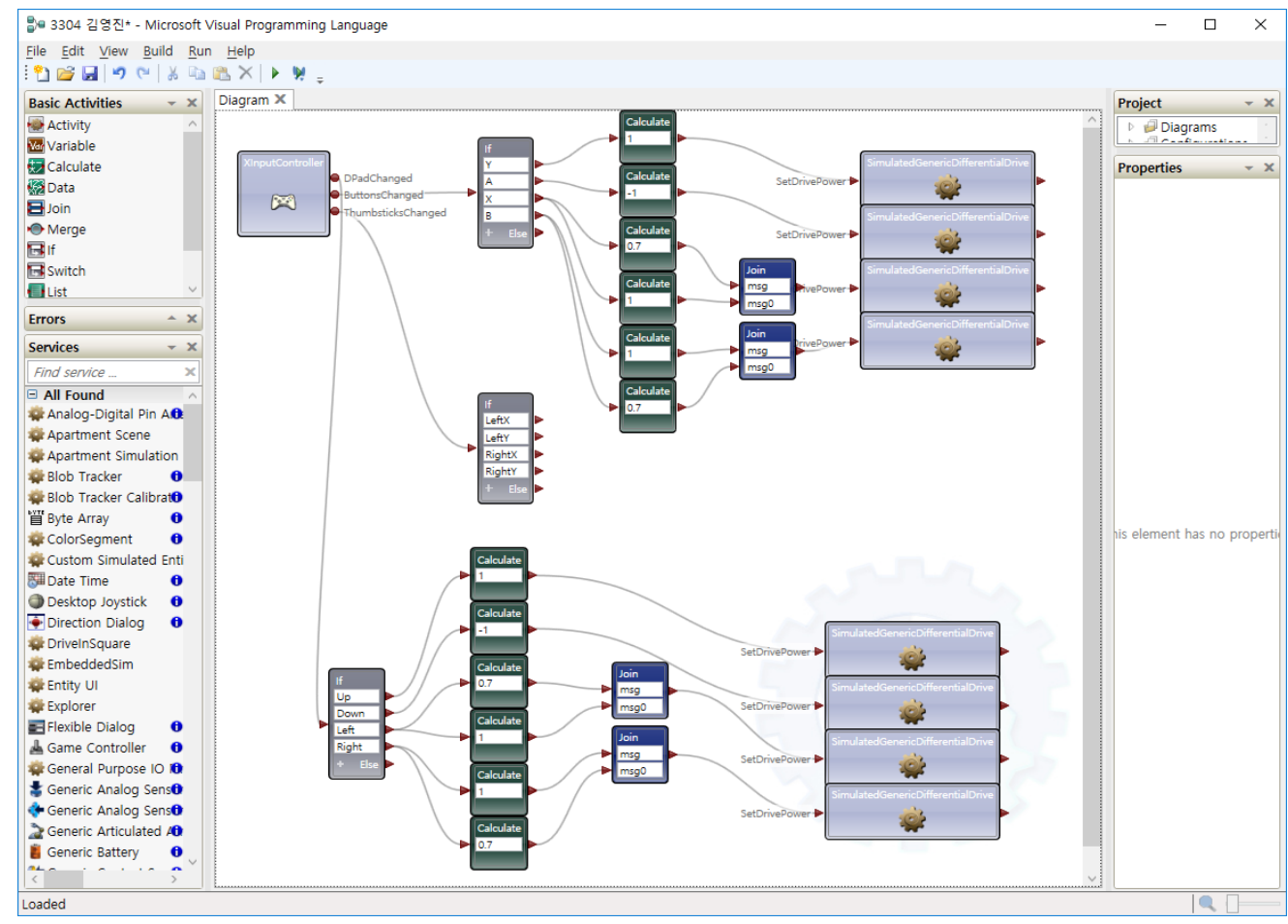

Figure 4. Source Code Programming by VPL (Level High)

App Inventor was a project to provide a developing environment to replace the existing programming languages in order to make it easy to develop applications that run on Android operating system [8]. As Figure 5 and Figure 6, App Inventor helps designing like an environment similar to smart phones, can take advantage of the sensor of smart phones, and can program with blocks as shown in Figure 7 and Figure 8.

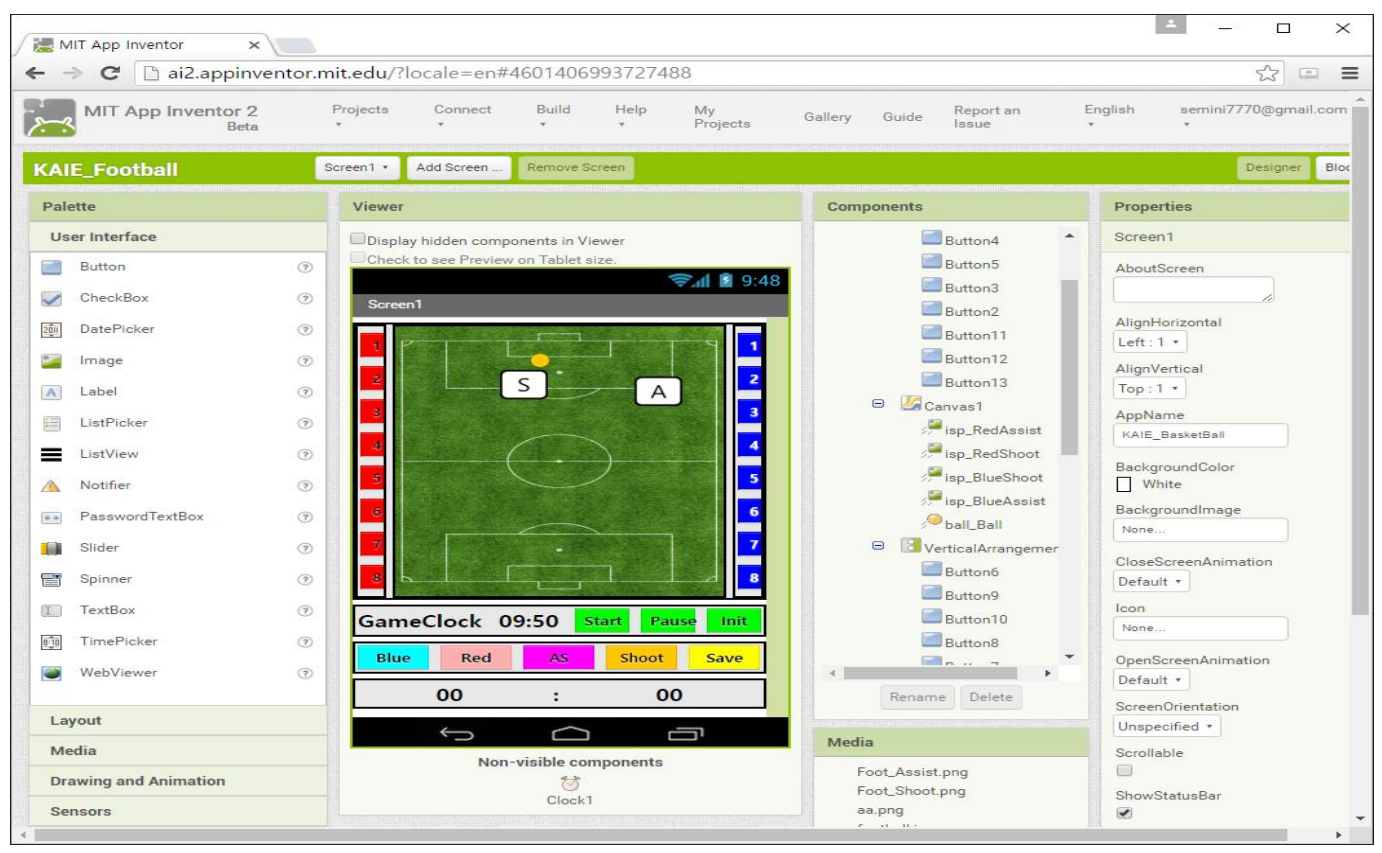

Figure 5. Design Screen of App Inventor (Level Low) 


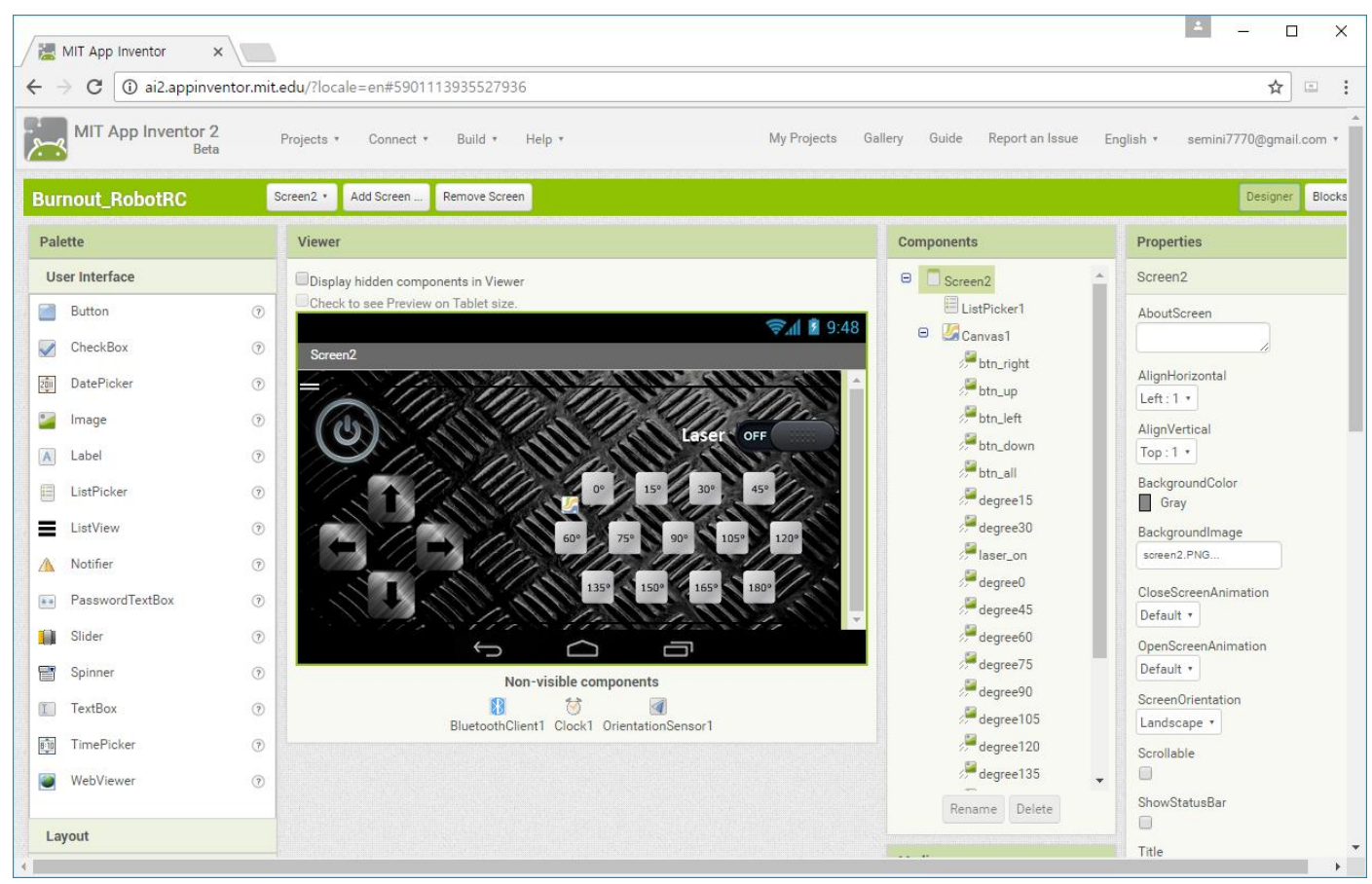

Figure 6. Design Screen of App Inventor (Level High)

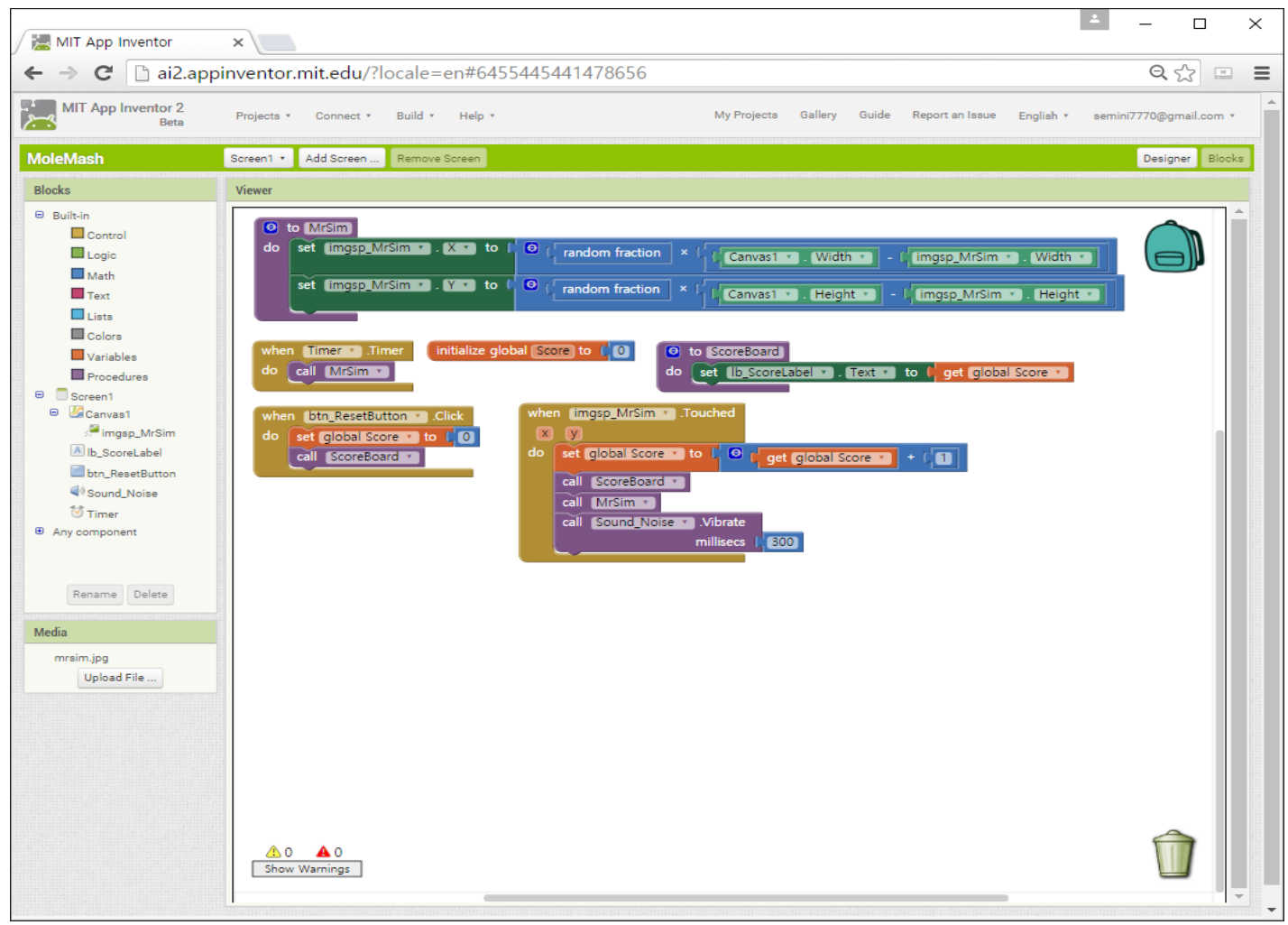

Figure 7. Block Programming Screen of App Inventor (Level Low) 


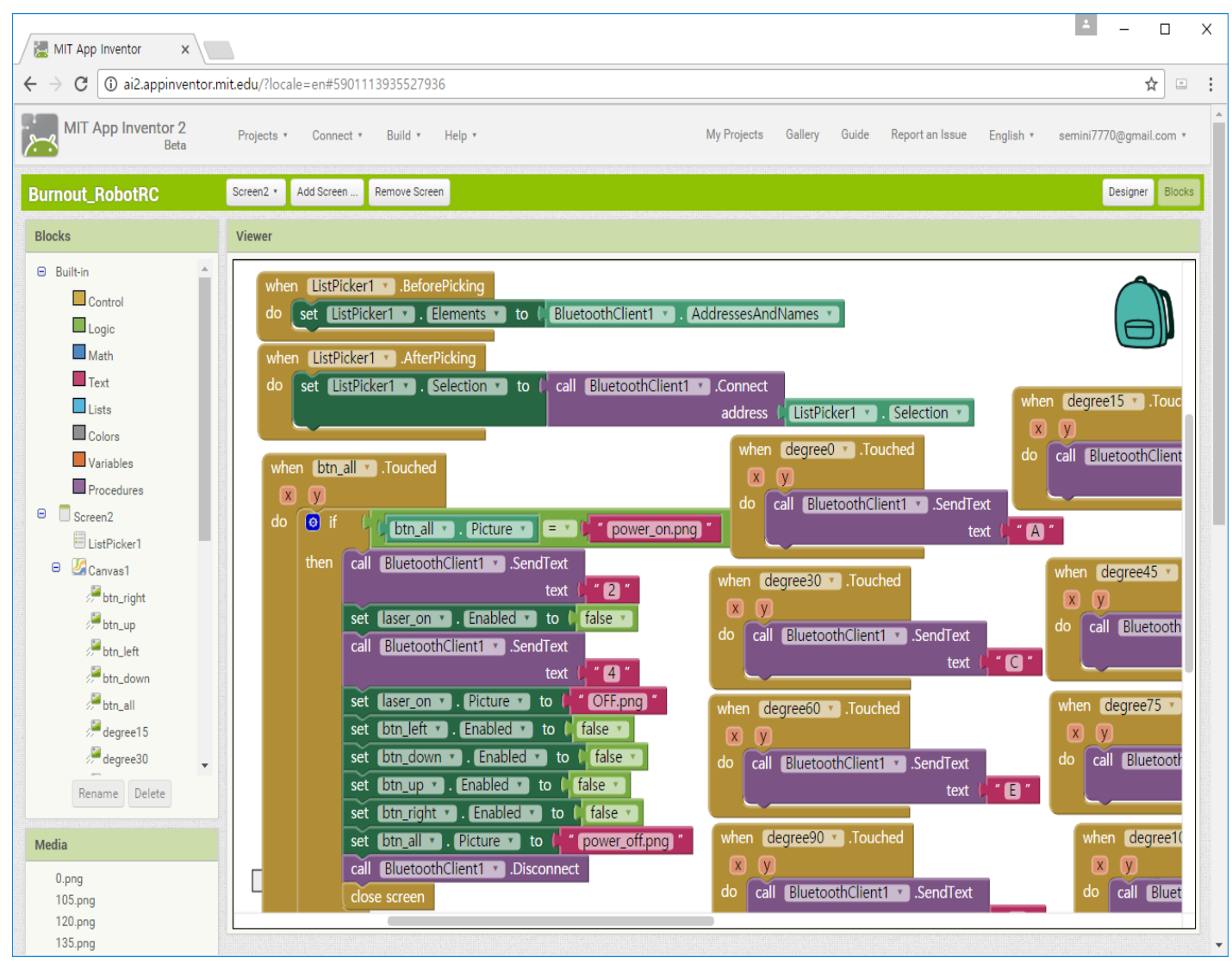

Figure 8. Block Programming Screen of App Inventor (Level High)

\section{Main Title}

\subsection{Subject of Study}

The subjects of this study were composed of 20 second year students of A technical high school and 20 second year students of B technical high school. All of the subjects were learning $\mathrm{C}$ language in other classes in the semester. The students of $\mathrm{A}$ technical high school learned App Inventor first and MSRDS later. The students of B technical high school learned MSRDS VPL first and then App Inventor. Their performances were evaluated every week with a given mission. In addition, the results of programming were commonly confirmed by a LEGO Mindstorm robot.

\subsection{Lesson Plan}

The Subjects were taught following the lesson plan like Table 1 and Table 2. "A course" was the plan before a mid-term examination, and "B course" was the plan before a final examination. In school A and B, "A course" and "B course" proceeded only by changing the order. 
Table 1. Lesson Plan (A Course)

\begin{tabular}{|c|l|}
\hline A Course & \multicolumn{1}{|c|}{ Contents } \\
\hline 1st week & MSRDS VPL basics \\
\hline 2nd week & basic Activity \\
\hline 3rd week & robotic simulation \\
\hline 4th week & variable \\
\hline 5th week & operator \\
\hline 6th week & input-output statement \\
\hline 7th week & control statement \\
\hline 8th week & Mid-term exam \\
\hline
\end{tabular}

Table 2. Lesson Plan (B Course)

\begin{tabular}{|l|l|}
\hline \multicolumn{1}{|c|}{ B Course } & \multicolumn{1}{|c|}{ Contents } \\
\hline 9th week & App Inventor basics \\
\hline 10th week & design \\
\hline 11th week & sensor utilization \\
\hline 12th week & variable \\
\hline 13th week & operator \\
\hline 14th week & input-output statement \\
\hline 15th week & control statement \\
\hline 16th week & Final exam \\
\hline
\end{tabular}

\section{Robot Programming Application in Classes and Result Analysis}

In this study, the units which had no matching points between both programming tools were excluded in the analysis. However, the performance assessment scores of students were measured for learning. The important result of this study was the part with similarities of the two programming languages and with the direct relationship of programming Logic. This corresponds to variables, operators, input-output statements, and control statements. The learning results of units would be analyzed as shown in Table 3 and Table 4.

The Students of A technical high school learned App Inventor first and then MSRDS. In general, the understanding of App Inventor has an average of $4 \%$ or higher. Because App Inventor was the programing language mostly similar to the interface of Scratch and Entry which was in recent trend, App Inventor might be familiar to the eyes of students and influenced mutual language intelligibility. Particularly in the section of variable of MSRDS VPL, there was the most gap, 4\% deviation of performance assessment because the procedure for setting variables in MSRDS VPL was more difficult than App Inventor. Therefore, if the use of programming language tools is difficult, the mutual language intelligibility will be lower. 
The students of B school learned MSRDS VPL first and then learned App Inventor. In general, the understanding of App Inventor was averaging 6\% or higher. Like A school students, there was the most deviation (3\%) in the variable section. However, A school's average percentage of mission performance was $87 \%$ and B school's $81 \%$. It can be said that A school's students who learned App Inventor first accepted another language more easily than B school's students who learned MSRDS first, and A school's students had a higher mutual language intelligibility than B school's students.

Table 3. Lesson Result of A School

\begin{tabular}{|l|c|}
\hline \multicolumn{1}{|c|}{ Week } & $\begin{array}{c}\text { A School } \\
\text { mission performer/total } \\
\text { (percentage) }\end{array}$ \\
\hline MSRDS VPL basics & $25 / 25(100 \%)$ \\
\hline basic Activity & $24 / 25(96 \%)$ \\
\hline robotic simulation & $24 / 25(96 \%)$ \\
\hline variable & $20 / 25(80 \%)$ \\
\hline operator & $23 / 25(92 \%)$ \\
\hline input-output statement & $20 / 25(80 \%)$ \\
\hline control statement & $21 / 25(84 \%)$ \\
\hline App Inventor basics & $25 / 25(100 \%)$ \\
\hline design & $24 / 25(96 \%)$ \\
\hline sensor utilization & $20 / 25(80 \%)$ \\
\hline variable & $24 / 25(96 \%)$ \\
\hline operator & $23 / 25(92 \%)$ \\
\hline input-output statement & $21 / 25(84 \%)$ \\
\hline control statement & $21 / 25(84 \%)$ \\
\hline
\end{tabular}

Table 4. Lesson Result of B School

\begin{tabular}{|l|c|}
\hline \multicolumn{1}{|c|}{ Week } & $\begin{array}{c}\text { B School } \\
\text { mission performer/total } \\
\text { (percentage) }\end{array}$ \\
\hline MSRDS VPL basics & $24 / 25(96 \%)$ \\
\hline basic Activity & $23 / 25(92 \%)$ \\
\hline robotic simulation & $22 / 25(88 \%)$ \\
\hline variable & $19 / 25(80 \%)$ \\
\hline operator & $20 / 25(80 \%)$ \\
\hline
\end{tabular}




\begin{tabular}{|l|l|}
\hline input-output statement & $20 / 25(76 \%)$ \\
\hline control statement & $19 / 25(76 \%)$ \\
\hline App Inventor basics & $24 / 25(96 \%)$ \\
\hline design & $24 / 25(92 \%)$ \\
\hline sensor utilization & $20 / 25(80 \%)$ \\
\hline variable & $22 / 25(88 \%)$ \\
\hline operator & $21 / 25(84 \%)$ \\
\hline input-output statement & $20 / 25(80 \%)$ \\
\hline control statement & $21 / 25(84 \%)$ \\
\hline
\end{tabular}

\section{Conclusions and Recommendations}

This paper studied the mutual language intelligibility between two visual programming languages and following results was obtained. First, because of App Inventor's similarity of structure to Scratch, App Inventer has an advantage in the mutual language intelligibility rather than MSRDS VPL. Second, a somewhat complicated procedure of setting like variables setting in SRDS VPL can affect the mutual language intelligibility. Third, after learning the programming language with a higher mutual language intelligibility than other existing programming languages, the learning can be helpful to study next programming languages. Although this study compared languages among icon or block-based programming languages, subsequent studies need to investigate the mutual language intelligibility of the existing $\mathrm{C}$ language, Basic, Java, etc.

\section{References}

[1] D. K. Kim, H. C. Lee, Y. W. Lee and S. Y. Shin, "Instructor's Smart Learning Acceptance : Focusing on TAM Model", Journal of the Institute of Information and Communication Engineering. Vol 20, no 6, (2016), pp 1081-1086.

[2] S. M. Chung, J. H. Choi and J. W. Park, "Design of Software Quality Evaluation Model for IoT", Journal of the Institute of Information and Communication Engineering, Vol 20, no 7, (2016), pp. 13421354.

[3] J. S. Lee, "Effects of LOGO Programming Language on Elementary School Students' Creativity", Jeonju National University of Education, M.A. (2008).

[4] K. S. Oh and S. J. An, "A Study on Development of Educational Contents about Computational Thinking”, Vol 19, no 2, (2016), pp. 11-20.

[5] C. J. Park, J. S. Hyun, H. R. Jin and H. S. Chung, "Relation Analysis of High School Students' Abstract Thinking, Language Familiarity and Academic Achivement of C and Scaratch Program Understanding", The Journal of Korean Assosiation of Computer Education, Vol 18, no 6, (2015), pp. 1-12.

[6] S. W. Seo, D. S. Nam and T. W. Lee, "The Effect of Computational Thinking Ability Using Text-base vs. Visual-base Programming Language on Robot Programming Learning”, Proceedings of $26^{\text {th }}$ Korean Association of Computer Education, Seoul, Korea, (2010), August 15-16.

[7] T. G. Yang and H. Y. Lee, "Visual Programming Language's Basic of Microsoft Robotics Developer", C\&Robot, Daejoen Korea, (2008).

[8] S. J. An and Y. J. Lee, "Elementary and Secondary Programming Education Plan Using App Inventor", The Journal of Korean Association of Computer Education, Vol 17, no 5, (2014), pp. 79-88. 


\section{Authors}

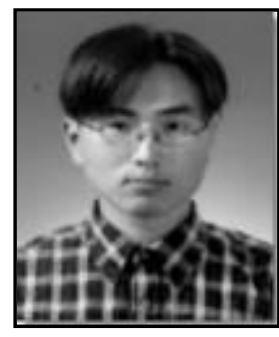

Se-Min Kim received his B.S. and M.S. Degrees from the Department of Computer Education at Woosuk University, Wanju, South Korea, in 2003 and 2006, respectively. He has been a Ph.D. Candidate in Graduate School of Information Communication Engineering from Hanbat National University, Daejeon, South Korea since 2014. He started working at New Vision, CO. LTD, in 2008, where he now works as a senior researcher. His current research interests include Computer Education, Robot Education, STEAM and Mobile Application.

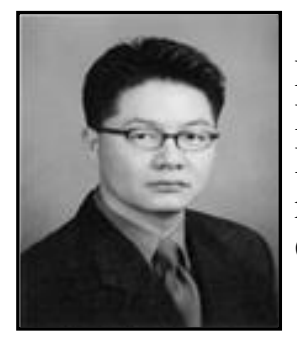

Chang-Su Ryu received his M.S and Ph.D. Degrees in Computer Education, Computer Engineering from Mokwon University, Daejeon, Korea in 2006 and 2013. He is currently a Professor of the Department of Cartoon and Animation in Yewon Arts University. His research interests include Animation, Mobile 3D Game, Computer Graphic and Robotics.

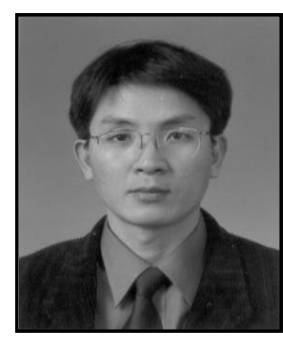

Choong Ho Lee received his B.E. and M.E. Degrees ins Electronic Engineering from Yonsei University, Seoul, Korea, in 1985 and 1987, respectively. He also received his Ph.D. Degree in Information Science from Tohoku University, Sendai, Japan in March of 1998. From 1985 to 2000, he was with KT as a researcher. Since 2000, he has been a Professor in Graduate School of Information Communication Engineering, Hanbat National University. His current research interests include pattern recognition, digital image processing and mobile robot control. 